\title{
Results of 24 hour ambulatory monitoring of electrocardiogram in 131 healthy boys aged 10 to 13 years $^{\star}$
}

\author{
OLIVE SCOTT, G J WILLIAMS, G I FIDDLER \\ From the Department of Paediatric Cardiology, Killingbeck Hospital, Leeds
}

SUMMARY Ambulatory monitoring of the electrocardiogram was performed in 131 healthy boys aged between 10 and 13 years for two consecutive periods of 24 hours. When awake the maximal heart rates ranged from 100 to 200 and the minimal from 45 to 80 beats per minute. During sleep maximal rates were 60 to 110 beats and minimal rates 30 to 70 beats per minute. Sinus arrhythmia was seen in every boy and in $36(27.5 \%)$ no other changes were found. Sinuatrial block, Mobitz type I, was not seen. Sinuatrial block, Mobitz type II, occurred twice only. Complete sinuatrial block occurred in 8.4 per cent, never lasted more than one cycle, and was always followed by a junctional beat.

First degree atrioventricular block occurred in 8.4 per cent and Mobitz type I atrioventricular block in 10.7 per cent. Premature beats were always single, atrial in 13 per cent, ventricular in 26 per cent, and except in two boys were never more than four in 24 hours. There were no episodes of ventricular or supraventricular tachycardia.

Changes in $\mathbf{P}$ wave morphology were common and slow junctional rhythm occurred in 13 per cent during sleep.

In the past, diagnoses of arrhythmias in childhood were made from the resting surface electrocardiogram taken for short periods, and often depended on chance recordings. Since 24 hour ambulatory monitoring on magnetic tapes became available, the tendency has been to interpret them in the same way as resting electrocardiograms despite the fact that they are recorded with the patient awake or asleep, during exercise or rest, and with the patient in the erect, prone, or supine positions. The findings on 24 hour ambulatory electrocardiographic tape recordings in normal healthy adults have been published. ${ }^{1-3}$ So far there are no reports of the findings in normal healthy children. This study was undertaken to define the characteristics of the electrocardiogram over 24 hour periods in normal healthy boys.

\section{Methods}

Recordings were made for two consecutive periods of 24 hours in 131 healthy boys whose ages ranged

* This work was supported by a grant from the British Heart Foundation.

Received for publication 20 December 1979 from 10 to 13 years. The boys had no symptoms and were questioned particularly about fainting attacks or loss of consciousness. A full clinical examination was carried out by one of us (OS) and no cardiac abnormality was detected in any of the subjects.

One chest electrode was placed on the upper part of the sternum and the other in the position of chest lead V4. They were firmly fixed to the skin without any air trap, taped down, and connected to a battery-operated Oxford Instruments miniature analogue tape recorder. The cassette was housed in a leather bag worn round the waist. Diaries were kept by the boys who noted their activities at particular times and the time of going to bed so that these could be correlated with findings on the tapes. They led normal lives and continued all usual sports except swimming. Analysis was carried out using the Oxford Medical Systems Analyser which automatically detects changes in heart rate or rhythm from preset RR intervals. The equipment incorporated a "synclock" mechanism to avoid variations in tape speed which would produce artefactual rhythm or rate patterns. Printouts were made of any abnormalities and at 
four hourly intervals throughout the trace for 10 second periods even when no abnormality was found.

The heart rate was recorded from the tapes at 30 minute intervals. The rate varied at each recording. It is important to state that none of the lowest or highest rates ever lasted more than half an hour.

In 17 of the 131 boys $(13 \%)$ the initial recordings were unsatisfactory. In four the electrodes were displaced, in eight the leads were broken; five of the tapes had been unwound by the boys and damaged. All were repeated and satisfactory tracings obtained; our observations are reported as mean ranges over 24 hours.

The following observations were made from the analysis of each tape:

(1) The highest and lowest heart rates, awake and asleep.

(2) Sinus arrhythmia (a gradual increase and decrease in PP intervals).

(3) Abnormal $P$ waves during the day and night, their duration, and the heart rates associated with abnormal $\mathbf{P}$ waves. When abnormal $\mathbf{P}$ waves occurred over three or more successive beats, this was defined as junctional rhythm.

(4) Sinuatrial block. This was classified using conventional criteria. ${ }^{4-6}$ In Type I PP intervals are equal but occasional beats are dropped; the interval between the $P$ waves surrounding the dropped beat is less than that of two cycles (Mobitz type I sinuatrial block). In Type II the interval between the $\mathbf{P}$ waves surrounding a dropped beat is equal to twice the PP interval between normal beats (Mobitz type II sinuatrial block).

Complete sinuatrial block in which there is failure of impulse formation in the sinuatrial node, or if the impulse is formed it is not conducted into the atrium.

(5) First degree heart block (a PR interval of $0.20 \mathrm{~s}$ or more).

(6) Second degree heart block. This was subdivided into two groups.

(a) Type I (Wenckebach phenomenon) (Mobitz type I). A dropped beat occurring after progressive increase in the PR interval.

(b) Type II (Mobitz type II) in which a dropped beat occurred without any changes in the PR interval.

(7) The presence of premature beats, ventricular or atrial.

\section{Results (Table 1)}

Of the 131 boys, 36 showed no abnormalities and remained in sinus rhythm throughout the recording.
(1) HEART RATES

The lowest and highest heart rates are shown in Fig. 1a during sleep and Fig. 1b when awake. The maximal heart rates ranged from 100 to 200 beats per minute when awake. The high rate of 200 occurred in only one patient and was a sinus tachycardia. The minimal rates were from 45 to 80 . During sleep maximal rates ranged from 60 to 110 and the minimal rates from 30 to 70 beats per minute.

\section{(2) SINUS ARRHYTHMIA}

This was present in every tracing and sinus pauses as long as $1.6 \mathrm{~s}$ occurred in six subjects at night when the heart rates were slow. The presence of sinus arrhythmia caused some difficulty when interpreting abnormalities such as second degree block type I (Wenckebach) and finding varying PP intervals in addition (Fig. 2).

\section{(3) ABNORMAL P WAVES}

Changes in the form of $P$ waves occurred in 44 boys $(33.6 \%)$, during sleep only in $20(15.2 \%)$, when awake only in seven $(5.3 \%)$; in three the $P$ wave changed during exercise. In 17 boys (13\%) the $\mathbf{P}$ waves altered during the day and night, usually becoming inverted or flat. In $17(13 \%)$ the abnormal $P$ waves were associated with junctional rhythm (Fig. 3), varying from three successive beats to periods of 25 minutes. During sleep the junctional rhythm was associated with slow heart rates.

\section{(4) SINUATRIAL BLOCK}

Mobitz type I sinuatrial block was not seen. Mobitz type II sinuatrial block was seen twice only and occurred only twice in each boy during sleep (Fig. 4). Complete sinuatrial block was seen in 11 boys $(8.4 \%)$. The block lasted for one cycle only, was always followed by junctional beats, and in

Table 1 Summary of findings on 24 hour electrocardiograms in 131 healthy boys aged 10 to 13 years

\begin{tabular}{llr}
\hline $\begin{array}{l}\text { Rhythm at lowest } \\
\text { heart rates }\end{array}$ & $\begin{array}{l}\text { Sinus } \\
\text { Junctional }\end{array}$ & $\begin{array}{r}114 \\
17\end{array}$ \\
Sinuatrial block with junctional escape & & 11 \\
First degree atrioventricular block & & 11 \\
$\begin{array}{l}\text { Second degree atrioventricular block } \\
\text { Mobitz type I } \\
\text { Mobitz type I (2:1 block) }\end{array}$ & 14 \\
$\begin{array}{l}\text { Premature } \\
\text { beats }\end{array}$ & & 1 \\
& Atrial & 10 \\
\hline
\end{tabular}


two was followed by slow junctional rhythm (Fig. 3). It never occurred more than three times over a 24 hour period, and in two subjects it occurred once only. In three patients the block occurred during the day, in six at night, and in two both day and night.

Fig. 1 Lowest and highest heart rates (a) during sleep. (b) while awake.
(5) FIRST DEGREE HEART BLOCK

This occurred in $11(8.4 \%)$ of the 131 boys, in seven $(5.3 \%)$ during sleep only. In four of these, Mobitz type I atrioventricular block developed during sleep, with heart rates between 40 and 55 per minute (Table 2).

客
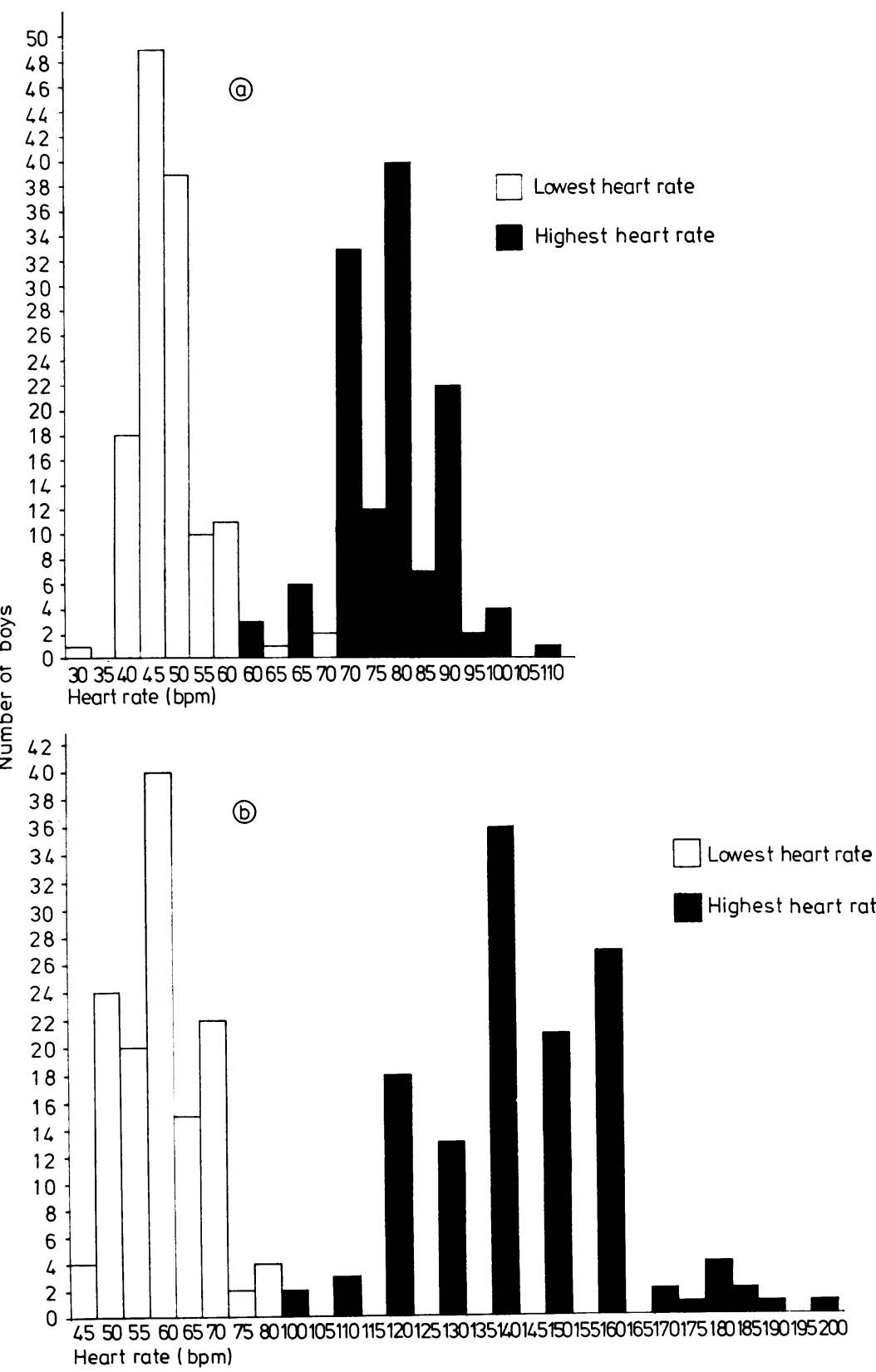
(6) SECOND DEGREE ATRIOVENTRICULAR BLOCK

Type I (Wenckebach) occurred in 14 boys $(10.7 \%$ ) (Fig. 2), 12 at night, and two during the day. Four of these also had first degree heart block while asleep. The heart rates during the periods of block varied from 40 to 60 per minute. The frequency of occurrence of the block varied from two to four times in 24 hours except in one boy in whom it occurred 54 times over 24 hours; 2:1 block was seen in one boy during sleep and occurred only once (Fig. 5). Type II (Mobitz II) was not seen.

\section{(7) PREMATURE BEATS}

Single premature ventricular beats occurred in 34 boys $(26 \%)$, in 20 while awake only, in six of these during exercise. In seven boys they were evident during sleep only and in seven during sleep and when awake. The number of premature beats in 24 hours was between one and four except in two boys, one of whom had 35 premature beats in 24 hours including a period of coupling lasting for nine seconds. The other had 27 premature beats over 24 hours. In one boy the premature beats were unifocal but in the others where more than one occurred, they were multifocal. Atrial premature beats occurred in 10 boys $(13 \%)$. They were always single, in four during sleep, in six when awake. There were never more than two in 24 hours except in one boy who had two half-hour periods of coupling during sleep.

\section{Discussion}

It is essential that the normal 24 hour electrocardiogram in healthy children is defined before we try to make definitive diagnoses from it in symptomatic children. Such data have not previously been reported in children. Data from adults cannot be applied to children.

The slow rates which occur in healthy boys are of importance. Our values of minimal heart rates when awake are similar to those in male medical students ${ }^{1}$ but the range is greater than found in studies in adults aged 16 to 65 years. ${ }^{2} 3$ Presumably the slow rates during sleep are the result of increased vagal tone and sympathetic withdrawal. Such episodes of bradycardia during a 24 hour period should not be regarded as indicating sinus node disease.

Complete sinuatrial block never lasted more than one cycle so the occurrence of longer periods of sinus arrest is likely to be significant, particularly if associated with the classical history of syncope on extreme exertion suggestive of sinus node disease in the young. Our tracings were measured carefully

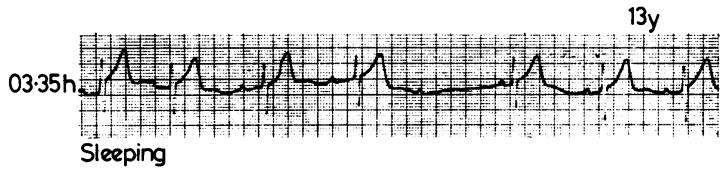

Fig. 2 Sinus bradycardia with sinus arrhythmia (cycle length 96 to 124) and type I second degree block (Wenckebach).

$11 y$

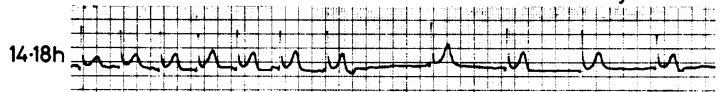

Fig. 3 Complete sinuatrial block, sinus rhythm, then pause greater than preceding cycle lengths. Subsequent $P$ waves poorly defined-slow junctional rhythm.

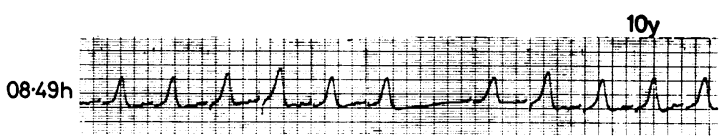

Fig. 4 Mobitz type II sinuatrial block. Shortening of $P R$ interval after the pause is probably related to length of time allowed for recovery of atrioventricular conduction-it gradually lengthens again.

Table 2 First degree heart block

\begin{tabular}{llll}
\hline PR interval $(s)$ & $\begin{array}{l}\text { Lowest heart } \\
\text { rate during } \\
\text { sleep }\end{array}$ & $\begin{array}{l}\text { Frequency of Mobitz } \\
\text { type I second degree block }\end{array}$ \\
\cline { 1 - 2 } Awake & Asleep & & \\
\hline 0.12 & 0.3 & 40 & One episode during sleep \\
0.18 & 0.24 & 48 & One episode during sleep \\
0.21 & 0.22 & 44 & Twice during sleep \\
0.22 & 0.30 & 40 & 54 times during sleep \\
0.14 & 0.24 & 40 & \\
0.10 & 0.21 & 40 & \\
0.18 & 0.22 & 44 & \\
0.14 & 0.21 & 54 & \\
0.12 & 0.24 & 45 & \\
0.14 & 0.21 & 45 & \\
0.12 & 0.21 & 55 & \\
\hline
\end{tabular}

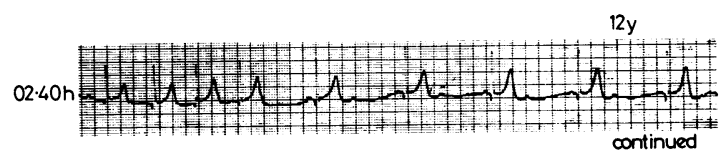

Fig. 5 Second degree (2:1) atrioventricular block. 
for evidence of Mobitz type I sinuatrial block but it was not seen.

First degree atrioventricular block was always associated with bradycardia, especially during sleep. Second degree atrioventricular block Mobitz type I was a surprising finding and was commoner in our series $(10.7 \%)$ than in the series of 50 medical students $(6 \%)^{1}$ and than in older age groups $(2.3 \%)^{2}$. In another series of adults it was not seen. ${ }^{3}$ It was always associated with bradycardia and occurred at night in 12 of 14 boys. Again increased vagal tone causing depression of the atrioventricular nodal conduction was probably responsible. This Wenckebach atrioventricular block has also been reported in Olympic athletes ${ }^{7} ; 2: 1$ block occurred once (Fig. 5). Mobitz type II atrioventricular block was not seen.

The occurrence of premature beats and their incidence over 24 hours was much less frequent in boys of 11 to 13 years than in adults. The R-on-T phenomenon was never seen nor were episodes of ventricular or supraventricular tachycardia both of which have been observed in healthy adults (16 to 65 years). ${ }^{2} 3$

Alteration in form and direction of $P$ waves in the standard resting electrocardiogram is uncommon. Our impression when we first used 24 hour ambulatory recordings that such changes in $P$ wave morphology were common has been confirmed. It is important not to overinterpret the significance of these changes when the recording is from a single lead and the patient's position is changing.

From the clinical point of view the results of this study are helpful. It seems that runs of premature beats are likely to be of pathological significance in this age group, as are episodes of ventricular or supraventricular tachycardia. Complete sinus arrest lasting more than one cycle is likely to be abnormal. Second degree atrioventricular block Mobitz I (Wenckebach phenomenon) cannot be regarded as evidence of disease; its association with bradycardia suggests that it is probably a manifestation of increased vagal tone. Sinus bradycardia and changes in $\mathrm{P}$ wave morphology on 24 hour recordings cannot be regarded as evidence of sinus node dysfunction. These findings on the standard electrocardiogram recorded at rest have been listed as suggestive evidence of sinus node dysfunction ${ }^{8}$ but the dynamic single lead 24 hour recordings cannot be interpreted in the same way. Further studies are required in other age groups and are at present in progress in boys aged between 14 and 16 years.

\section{References}

1 Brodsky M, Wu D, Denes P, Kanakis C, Rosen KM. Arrhythmias documented by 24 hour continuous electrocardiographic monitoring in 50 male medical students without apparent heart disease. $\mathrm{Am} \mathcal{F} \mathrm{Cardiol}$ 1977; 39: 390-5.

2 Clarke JM, Hamer J, Shelton JR, Taylor S, Venning GR. The rhythm of the normal human heart. Lancet 1976; ii: 508-12.

3 Kostis JB, Moreyra AE, Natarajan N, et al. Ambulatory electrocardiography: what is normal? (abstract). Am $\mathcal{F}$ Cardiol 1979; 43: 420.

4 Krikler DM, Curry PVL. Electrocardiographic features of cardiac arrhythmias. In: Hamer J, ed. Recent advances in cardiology. London, Edinburgh, New York: Churchill Livingstone, 1977: 81-101.

5 WHO/ISC Task Force. Definition of terms related to cardiac rhythm. Am Heart $\mathcal{F}$ 1978; 95: 796-806.

6 Zipes DP. Second degree atrioventricular block. Circulation 1979; 60: 465-72.

7 Meytes I, Kaplinsky E, Yahini J, Hanne-Paparo N, Neufeld HN. Wenckebach A-V block: a frequent feature following heavy physical training. Am Heart $\mathcal{f}$ 1975; 90: 426-30.

8 Scott O, Macartney FJ, Deverall PB. Sick sinus syndrome in children. Arch Dis Child 1976; 51 : 100-5.

Requests for reprints to Dr Olive Scott, Killingbeck Hospital, York Road, Leeds LS14 6UQ. 